\title{
Bond Pricing and Immunization Strategy - Asset Allocation in Bond Investment
}

\author{
Yuyao Wang ${ }^{1, a, \uparrow}$ Bixia $\operatorname{Han}^{2, b, \uparrow}$ \\ ${ }^{1}$ Rutgers Newark College, Northeast Normal University, Changchun, 130000, China \\ ${ }^{2}$ School of Management, Xiamen University, Fujian Province, 361005, China \\ awangyy085@nenu.edu.cn, b33120182202082@stu.xmu.edu.cn \\ ${ }^{\dagger}$ These authors contributed equally.
}

\begin{abstract}
Asset allocation is a widely used financial term that fits most people. However, even in the most basic concept of asset allocation, there is still existing risk or uncertainty. This paper aims to discuss the impact of different influencing factors on bond pricing in the bond market and then further discuss the risk aversion strategy that can be analyzed through the duration, also known as the immunization strategy. We also conduct sensitivity analysis of four different situations, changing different yield rates and coupons and changing increasing yield rates and coupons at a certain rate. This paper found that different yield rates, different coupons, and increasing yield rates have a linear relationship with the bond price. In contrast, the increasing coupon with a certain ratio has a nonlinear relationship. Through immunization strategy, it can develop an asset portfolio composed by a certain ratio. Also, using the immunization strategy can reduce the risks that investors need to take and maximize their interests to a certain extent. The combination of a certain percentage of zero-coupon government bonds and corporate bonds effectively shields investors from risk. This paper constructs the issue of bond pricing, which is of practical significance for investors to evaluate their risk-bearing ability and purchasing ability and to use the immunization strategy of hedging risk.
\end{abstract}

Keywords: Bond Price, Duration, Immunization strategy, Investment portfolio.

\section{INTRODUCTION}

Bonds are one kind of debt security issued in connection with a borrowing arrangement that obligates the issuer to make specified payments to the bondholders on specified dates [1]. Among all debt securities, including those in the money market and the capital market, bonds are among the most common long-term debt securities traded in the capital market. A developed bond market can provide local firms with access to direct financing, enhance the liquidity of the overall market and reduce systematic risk in the market [2]. Therefore, given the importance of the bond market, how to price bonds traded in the bond market precisely is one top priority for the healthy and sustainable development of the bond market.

Moreover, bonds traded in the capital market are exposed to various kinds of risks, including default risk, liquidity risk, and interest rate risk, and so on. For most bond portfolio managers, the sensitivity of bond prices to changes in market interest rates, that is, interest rate risk is of greatest concern. Therefore, many investors turn to various bond management strategies to protect their bond portfolio from interest rate risk. There are overall two categories of bond management strategies: passive strategy and active strategy. This article will mainly focus on immunization strategy, one passive bond management strategy used by many financial and funds institutions.

Next, we will review the literature on bond pricing and immunization strategy. For defaultable bonds, general pricing methods can be divided into two main categories: structural models originated from the pricing model proposed by Merton and reduced-form models or intensity models. Merton presented a simplified model that can value each component of the firm's liability mix. Despite being simple and innovative, Merton's pricing model was inevitably subject to its simplified assumptions about its liability structure and costless bankruptcy. Therefore, many scholars, including Black and Cox, Leland and Fan, and Sundaresan, had incorporated more realistic assumptions into the Merton model [3]. For the default-free bond, Longstaff and 
Schwartz found that the risk of a default-free bond stems from two major sources: interest rate shifts and changes in bond market volatility, and that changes in the volatility of interest rates have the greatest impact on the prices and yields of intermediate-term bonds [4].

Over the past few decades, there are lots of studies focusing on bond portfolio management. Redington, in 1952 first introduced the concept of immunization based on the assumption of flat term-structure [5]. Later, Fisher and Weil in 1971 modified Redington's approach and expanded immunization strategy by taking into account the natural shifts of interest rate [6]. After 1971, several more advanced theories about immunization strategies were continuously proposed, including Bierwag and Khang's maximin theory, Leibowitz and Weinberger's contingent immunization, and Bierwag and Khang's multiple shocks, and so on.

In the paper, we first introduced discounted cash flow concepts, duration, and modified duration. Secondly, we listed the pricing methods, including zero-coupon bonds, fixed-rate coupon bonds, and floating-rate coupon bonds. And then conducted a sensitivity analysis of bond prices when changing bond yield rates and coupon rates, respectively. After that, we studied one passive bond management strategy, immunization strategy, and conducted an empirical test to construct one real situation where one investor needs to construct his bond portfolio to fund future payment and test the effectiveness of immunization strategy. In the last, we listed some limitations about immunization strategy.

As for the sensitivity analysis found that bond prices and bond yields generally show an inverse relationship. When other conditions remain unchanged, as the yield rate increases at the same amount, the bond price falls at a certain rate; while the yield rate increases at a certain rate, the price of the bond falls more and more sharply. It is generally a positive correlation between bond price and coupon. When other conditions remain unchanged, as the coupon (coupon rate) increases at the same amount, the price of the bond increases at a certain rate, while the coupon (coupon rate) increases at a certain rate, the price of the bond goes up more and more dramatically. As for the empirical test, we found that one constructed bond portfolio can be immunized from the fluctuation of interest rate when the interest rate changes insignificantly. But as time goes by, the duration of bonds and the duration of liability do not match, which means that the investors need to rebalance their bond portfolio.

The remainder of the paper is organized as follows: Section 2 describes basic background about bond pricing, Macaulay duration, and immunization strategy; Section 3 introduces bond pricing methods for different kinds of bonds and performs one sensitivity analysis of bond prices; Section 4 describes modified duration based on the Macaulay duration; Section 5 introduces immunization strategy, conducts an empirical test for immunization strategy and mentions immunization strategy's limitations; Section 6 presents our conclusions.

\section{BACKGROUND DESCRIPTION}

Macaulay duration is of great significance to bond pricing. The calculated Macaulay duration can be combined with an immunization strategy to help investors avoid risks [7].

According to Frederick Robertson Macaulay's research, bond interest rate, maturity period, and yield to maturity are closely related to bond price. He proposed five theorems of bond pricing that are still regarded as classic nowadays.

In this research, we conduct about the relationship between bond price and different factors. Generally speaking, bond pricing is divided into two dimensions: internal and external factors. Internal factors include the face value, the coupon interest; the validity period; whether it can be redeemed in advance; whether it is convertible; liquidity, and the possibility of default. External factors include risk-free interest rates, market interest rates, and inflation rates [8].

Bond price always depends on his present value. The present value in accounting measurement refers to the future cash flow value after being discounted at an appropriate rate. It is a measurement attribute that considers the time value of money. To understand how to price a particular bond, the concept of present value should be introduced first, which is needed to be obtained in the calculation and has some practical significance for the understanding duration. Generally speaking, there are two big categories of bonds: fixed-rate bonds and floating-rate bonds. A zero-coupon bond is a kind of fixed-rate bond where the coupon rate equals zero. This kind of bond is issued at a discount, does not carry coupons, and pays a lump sum of principal and interest at face value on maturity.

The immunization strategy is aimed to manage the bond portfolio. For any bond, interest rate fluctuations have opposite effects on long-term and short-term bonds [9]. By selecting a bond portfolio with a Macaulay duration equal to the maturity of its liabilities (cash outflow), the manager can ensure a fixed cash flow after a certain period by taking advantage of the offset characteristics of price risk and reinvestment risk.

This paper aims to propose an immunization strategy by integrating different bond varieties, which can lower the risk for the investors.

\section{PRICING THE BOND}

Bond pricing is for risk management, so as important as price is the sensitivity of the bond. For interest rate sensitivity, the most important is duration and convexity. 
Mathematically, you can use these two to approximate a bond as a quadratic function. More importantly, the values and symbols of the two reflect important characteristics of bonds. For example, the convexity of a normal bond is positive, but it's negative for mortgagebacked security (MBS). The reason is that when the interest rate is low, the price of ordinary bonds will rise, but the price of MBS tends to level off. When the interest rate is low, the buyers will choose to exercise the second loan to pay off the original high-interest mortgage, making it difficult for the price to exceed the parity.

This paper mainly discusses bond pricing based on mathematical methods, which uses interest rate and coupon to calculate the present value of bonds. In addition, this paper will compare the influence of different factors on the present value of bonds and combine the concept of duration to make a tentative plan of immunization strategy.

The following is the mathematical formula for the present value of bonds:

$$
P=\sum_{i=1}^{n} \frac{C^{n}}{(1+r)^{n}}+\frac{F}{(1+r)^{n}}
$$

where $\mathrm{C}$ is periodic coupon payment, $\mathrm{F}$ is the face value of a bond, $r$ is yield to maturity (YTM), $n$ is the number of periods to maturity.

The following formula is used to calculate the Macaulay duration [10]:

$$
D=\sum_{i=1}^{n} n \frac{\frac{C F_{n}}{(1+r)^{n}}}{P}
$$

where, $C F$ is periodic cash flow, $P$ is the present value of a bond, $r$ is yield to maturity (YTM), $n$ is the number of periods to maturity.

\subsection{Zero-Coupon Bond}

Based on the above pricing model, we discuss the different present values of various bonds such as a zerocoupon bond, fixed-rate bond, bond with an increased bond rate, and bond with different yield rates. Firstly, the zero-coupon bond is issued at a discount that does not carry coupons and pays a lump sum of principal and interest at face value on maturity. The biggest feature of zero-coupon bonds is that they avoid the risk of reinvesting the interest earned by the investor. Investors get a discount (that is, a discount to their face value) when they buy a zero-coupon bond and receive the face value at maturity. Because of these characteristics, zero-coupon bonds are particularly sensitive to changes in interest rates. In general, bond prices and interest rates change in an inverse relationship.

The following formula is used to calculate the zerocoupon bond:

$$
P_{0}=\frac{F}{(1+r)^{n}}
$$

$\mathrm{P}_{0}$ is the price of the zero-coupon bond, $\mathrm{F}$ is the face value of a bond, $r$ is yield to maturity (YTM), and $n$ is the number of periods to maturity.

When we plug the zero-coupon pricing formula into the general duration formula above, we get the following formula:

$$
D_{0}=n
$$

$D_{0}$ is the duration of a zero-coupon bond, $n$ is the number of periods to maturity.

\subsection{Fixed-Rate Bond}

Fixed-rate bonds are bonds that pay the same interest rate for the entire term of the bond. Investors can choose from fixed-rate bonds in the form of treasury bills, corporate bonds, municipal bonds, or certificates of deposit if they want a guaranteed interest rate for a specified period.

\subsection{Floating Rate Bond}

A floating rate fund is a fund that invests in financial instruments that pays a variable or floating interest rate [11]. A floating rate fund, which can be a mutual fund or an exchange-traded fund (ETF), invests in bonds and debt instruments whose interest payments fluctuate with an underlying interest rate level. Typically, a fixed-rate investment will have a stable, predictable income. However, as interest rates rise, fixed-rate investments lag behind the market since their returns remain fixed. Floating rate funds aim to provide investors with a flexible interest income in a rising rate environment. As a result, floating-rate funds have gained popularity as investors look to boost the yield of their portfolios.

Next, according to the pricing formulas given above, we want to investigate different factors'

\subsection{Sensitive Analysis}

This section mainly studied the sensitivity of bonds' value on different factors, including yield rate and coupon rate.

\subsubsection{Different Yield Rates}

Now assume that there are five different bonds, and they all have the same face value of $1000 \$$, coupon of $100 \$, 3$ years maturity. We are going to analyze the relationship between the yield to maturity and present value by using different yield rates: 


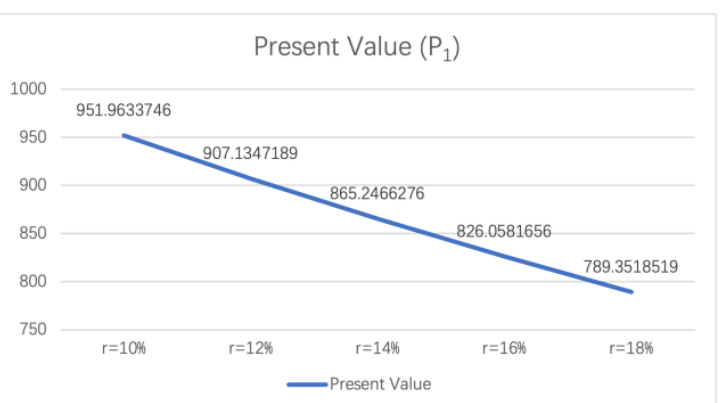

Figure 1 The relationship between different yield rate and bond price

The figure 1 shows that the bond price will decrease with the different yield rate growing at the same amount.

\subsubsection{Increasing Yield Rates}

Now make an assumption very similar to the one above, and there are five different bonds, and they all have the same face value of $1000 \$$, coupon of $100 \$, 3$ years maturity. We are going to analyze the relationship between the increasing yield to maturity and present value by using various yield rates at the increase rate $\mathrm{a}=10 \%$ :

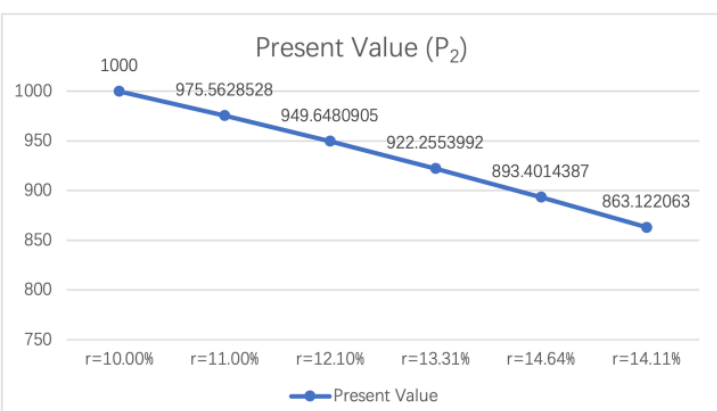

Figure 2 The relationship between increasing yield rate and bond price

Figure 2 shows that the bond price will decrease more and more sharply with the increasing yield rate, which is growing at a stated rate.

\subsubsection{Different Coupon Rates}

After discussing the relationship between the bond yield and the price, let's talk about another five different bonds, and they all have the same face value of $\$ 1000$, the yield rate of $10 \%, 3$ years maturity. We will analyze the relationship between the increasing coupon and present value by using various coupon rates of $10 \%$.

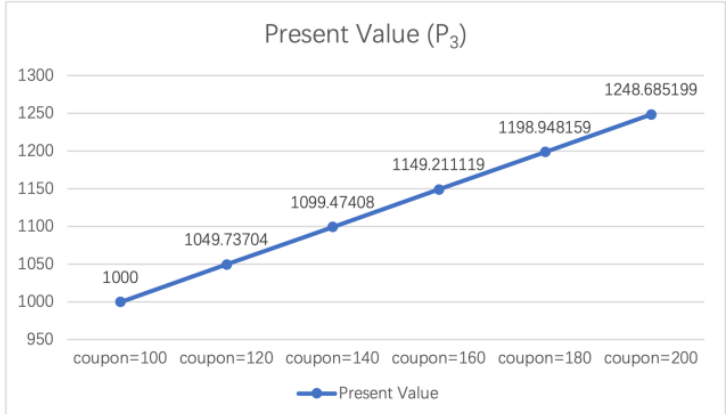

Figure 3 The relationship between different coupon (coupon rate) and bond price

Figure 3 indicates that the bond price will stably increase with the different coupons (coupon rate), growing at the same amount.

\subsubsection{Increasing Coupon Rates}

Five different bonds have similar conditions as we mentioned before, and they all have the same face value of $\$ 1000$, the yield rate of $10 \%, 3$ years maturity. We will analyze the relationship between the increasing coupon and present value by using various coupon rates of $10 \%$ and at the increase rate $\mathrm{m}=10 \%$.

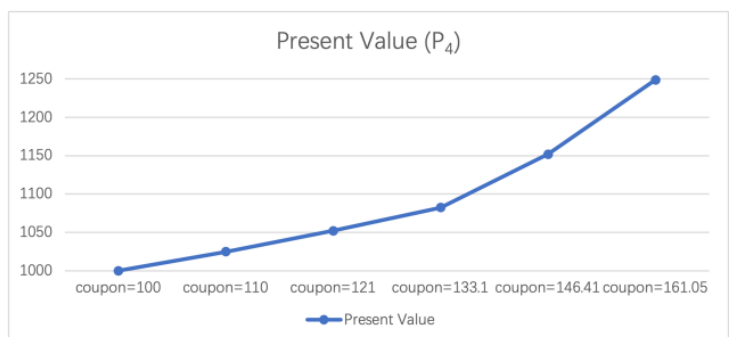

Figure 4 The relationship between increasing coupon (coupon rate) and bond price

Figure 4 indicates that the bond price will increase more and more sharply with the different coupon (coupon rate), which is growing at a stated rate.

In conclusion, we discussed the general relationship between bond prices and yield rate and coupon rate. Bond prices and bond yields generally show an inverse relationship. When other conditions remain unchanged, as the yield rate increases at the same amount, the bond price falls at a certain rate, while the yield rate increases at a certain rate, the price of the bond falls more and more sharply. There is generally a positive correlation between bond price and coupon. When other conditions remain unchanged, as the coupon (coupon rate) increases at the same amount, the price of the bond increases at a certain rate, while the coupon (coupon rate) increases at a certain rate, the price of the bond goes up more and more dramatically. 


\section{MODIFIED DURATION}

In this section, we introduced the concept of modified duration and gave the formula of it. What is more, based on the limitation of duration in estimating the bonds' price change, we discussed the advantage of using modified duration to calculate the percentage change of bonds' price when the interest rate changes. Modified duration is defined as

$$
D^{*}=\frac{D}{(1+y)}
$$

$y$ refers to the bond's yield to maturity; $D$ refers to the duration of one bond.

Modified duration derives from Macaulay's duration. Macaulay's duration measures the weighted average of the times to each coupon or principal payment, which indirectly implies the sensitivity of one bond to interest risk. Macaulay's duration can also be expressed as the following formula, that is,

$$
D=-\frac{\frac{\Delta P}{P}}{\frac{\Delta(1+y)}{(1+y)}}
$$

where $\Delta P$ refers to the monetary change of bond's price; $P$ refers to bond's price; $y$ refers to the bond's yield to maturity.

However, in reality, most investors care about the proportional price change when the bond's yield changes. Using duration to calculate the percentage of a bond's price change is not straightforward enough. Therefore, modified duration was proposed to gauge the changes in the value of an asset that occurs in response to a parallel shift in interest rates [12], which greatly simplifies the calculation of the percentage of bond's price change. By using modified duration, we can get the following formula, that is,

$$
D^{*}=\frac{D}{(1+y)}=\frac{\frac{\Delta P}{P}}{\Delta(1+y)}=\frac{\frac{\Delta P}{P}}{\Delta y}
$$

where, $\Delta P$ refers to the monetary change of bond's price; $P$ refers to bond's price; $y$ refers to the bond's yield to maturity.

From the perspective of calculus, the modified duration can be expressed as the first derivative of the bond's price with respect to changes in the bond's yield divided by bond price. Thus, the formula for the modified duration can also be expressed as:

$$
D^{*}=-\frac{1}{P} \times \frac{d P}{d y}
$$

In this way, the percentage of a bond's price change is just the product of modified duration and the change in bond's yield, which makes the calculation much easier than before.

\section{IMMUNIZATION STRATEGY}

In this section, we introduced one passive bond management strategy, that is, the immunization model clarified its main principles and gave its formula. Moreover, to test its immunization effect, we conducted one empirical test and drew the corresponding conclusion. Finally, we discussed its limitations.

\subsection{Immunization model}

Immunization strategy is one passive bond management strategy used by investors to shield their assets from exposure to interest rate risk. To be specific, this strategy seeks to establish a virtually zero-risk bond portfolio, in which interest rate fluctuation has no impact on the firm's value.

Before explaining the immunization strategy in detail, we need to clarify two components of interest risk first. In general, if the interest rate changes after one investor purchased one bond, he may be exposed to two specific risks. The first one is price risk, which means that the bond's terminal price will be affected by the interest rate change. Another one is coupon reinvestment risk resulting from reinvesting the coupons at interest rates different from the yield to maturity on the bond at the time of purchase. The total effect of these two risks varies in opposite directions when the interest rate changes. For example, when the interest rate increase, the price of a bond will decrease, while the reinvested yield of coupons will increase, and vice versa. [13]

Therefore, an effective immunization requires that these two opposite effects offset each other, thereby guaranteeing that the asset's future value will not be affected by the fluctuation of interest rate.

Actually, the concept of immunization was first proposed by F.M.Redington, an actuary for a life insurance company, in an article 'Review of the Principle of Life-Office Valuations' in 1952. He assumed a flat term structure and then showed that if the duration of an asset portfolio matched the duration of liabilities, changes in interest rates over time would affect the value of liabilities to the same extent as these changes affected the value of assets.[14]

There are overall two steps in using the immunization strategy. The first step is to match the duration of asset and liability investors hold in their portfolios. The same asset and liability duration implies that assets and liabilities have the same sensitivity to interest rate fluctuation.

The formula can be expressed as below:

$$
\sum_{i=1}^{n} D i \times w i=\sum_{j=i}^{m} D j \times w j
$$


$D_{i}$ refers to the duration of bond $i ; w_{i}$ refers to the portfolio share of bond $i ; D_{j}$ refers to the duration of liability $j ; w_{j}$ refers to the share of liability $j$.

The second step is to match the present value of assets and liabilities. These two rules can, to some extent, guarantee that assets' and liabilities' value change can offset against each other when interest rate fluctuates.

\subsection{Empirical test}

\subsubsection{Constructing the empirical model}

In this section, we made an empirical test to examine the effectiveness of the immunization strategy.

Try to assume that one student will need to make a one-off tuition payment of $\$ 17,000$ after three years from now. He wonders how to construct the portfolio to fund future payments. There are two kinds of bonds in the financial market:

The first is one zero-coupon government bond, with a face value of $\$ 100$, a current price of $\$ 85.48$, and remaining life of 4 years.

The second is one corporate bond, with a face value of $\$ 100$, the current price of $\$ 100$, an annual coupon of $\$ 4$, and remaining life of 2 years.

Assume all debt has the same level of default risk. The benchmark yield curve for fixed-income investments of the same riskiness is flat at a level of $4 \%$ p.a.

Using the Macaulay duration formula, we can calculate the duration of the zero-coupon bond and the corporate bond, respectively 4 years and 1.96 years.

What is more, the duration of the liability is three years.

For the duration is additive, we can construct the following formula to match the duration of assets and liabilities:

$$
w_{G B} \times 4+w_{C B} \times 1.9615=3
$$

where, $w_{G B}$ refers the proportion of zero-coupon government bond in the bond portfolio; $w_{C B}$ refers the proportion of coupon corporate in the bond portfolio.

$$
\begin{aligned}
& \mathrm{w}_{\mathrm{GB}}=50.94 \% \\
& \mathrm{w}_{\mathrm{CB}}=49.06 \%
\end{aligned}
$$

What is more, we can get the present value of the liability to be:

$$
\frac{17000}{(1+4 \%)^{3}}=15,112.94
$$

Therefore, we can get the present value and exact units of each bond we should hold. By multiplying the proportions of two bonds and the total money the investor has, we can get the respective total amount of each bond the investor should hold. And then, we know the price per unit of each bond, we can get the exact units needed to be bought.

Through the calculations, the units of government bond and corporate bond needed to be bought respectively are 90.07 and 74.14 .

Therefore, from the above working process, we can conclude that the student should allocate $50.94 \%$ of his fund to invest zero-coupon bond and $49.06 \%$ of his fund to invest corporate coupon bond to make the one-off payment three years later.

\subsubsection{Testing the effect of change of interest rate}

After constructing the portfolio, the next thing we need to do is to test its immunization effect, that is, whether this strategy can shield the portfolio from interest risk.

Therefore, we list several scenarios to simulate the fluctuation of interest rates in the market.

And in each scenario, we can calculate the value of assets after three years. The formula of the future value of assets is given below:

Future value of assets

$=$ value of zero-coupon bond + value of coupon bond

$$
=\frac{\text { face value of zero-coupon bond }}{(1+\text { discount rate })} \times \text { units }+
$$

$\frac{\text { annual coupon of corporate bond }}{(1+\text { discount rate })^{2}}+$

$\left.\frac{\text { annual coupon }+ \text { face value }}{(1+\text { discount rate })}\right] \times$ units

Figure 5 gives the sensitivity of the future value of assets on changes in the interest rate, in a wide range between $2.5 \%$ and $5.5 \%$.

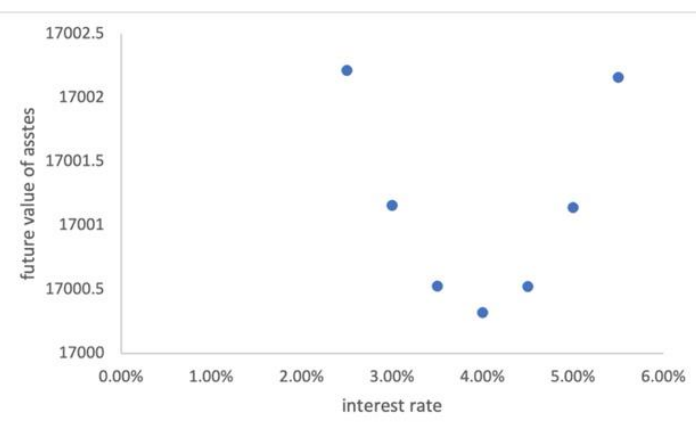

Figure 5 Sensitivity of Future Value on Changes in the Interest Rate

From the above graph, it can be easily observed that when the interest rate changes insignificantly, the future value of assets changes little, around $\$ 17000$, which means that despite the fluctuation of interest rate, the asset's future value can still keep unaffected. 


\subsection{Some limitations about immunization strategy}

According to the above analysis, there still exist some limitations to the immunization strategy. First, the duration of bonds will be affected by various factors, including bonds' residual maturity and interest rate, which can be directly seen through the formula of Macaulay duration. The change of interest rate will influence the expected stream of each future payment and thus the price of a bond. Thus, when the interest rate changes, the duration of one bond will inevitably vary. Even if we assume that the interest rate does not change, the bonds' duration will still change with time. For coupon bonds, duration generally decreases less rapidly than maturities dose. However, for the one-off payment liability, its duration equals its maturity. Thus, as time passes, bond portfolio and liability duration will fall at different rates [15].

Therefore, when these factors change, the duration of bonds varies as well. The duration of assets and that of liability become unmatched. The immunization strategy necessitates continuous rebalancing so that investors can guarantee that their portfolio is well immunized.

Secondly, because immunization strategy is based on duration, immunization strategy is inevitably subject to the limitation of duration. According to the modified duration formula, which directly derives from Macaulay duration, we know that it implies that the percentage of a bond's price change is directly proportional to the change in the bond's yield. However, if we draw the graph of the percentage change in bond price as a function of the change in its yield, it can be obviously found that the plot is not linear. For small changes in bond yield, the duration's approximation is quite accurate, while for significant changes in bond yield, the duration's approximation is inaccurate to some extent.

Thirdly, the immunization strategy mentioned before is based on the concept proposed by F.M.Redington. He assumed the term structure of interest to be flat so that the constant discount rate would be applied to discount all the cash flows generated by holding bonds.[16] However, this assumption is unrealistic because of the frequent shifts in the term structure of interest rates during the holding period. Therefore, Redington's measure of duration does not provide an accurate measure for changes in the pattern of the discount rate.

\section{CONCLUSION}

This paper mainly introduces the universality and practical significance of asset allocation, according to the bond pricing and duration calculation, using the sensitivity analysis and the idea of an immune strategy to make a specific bond allocation into an asset portfolio, to help investors to avoid risks.
This paper discusses three aspects: bond pricing modified duration and immunization strategy.

Firstly, we use sensitivity analysis to study the effect of yield rate and coupon rate on the bond price under different growth conditions. Secondly, we give some details on the modified duration to simplify the calculation of bonds' price change when a percentage change of bond's yield is given. To be more specific, the percentage of a bond's price change is just the product of modified duration and the change in the bond's yield. Thirdly, from the empirical test, it can be known that once the investor matches the duration of the bond portfolio and the duration of liability, the investor can shield his portfolio from the fluctuation of interest rate when it changes insignificantly. However, there are some limitations to the immunization strategy, including rebalancing, duration limitations, and the assumption of the flat term structure of interest. There is a possible portfolio of bonds by using the immunization strategy. The first is one zero-coupon government bond, with a face value of $\$ 100$, a current price of $\$ 85.48$, and remaining life of 4 years. The second is one corporate bond, with a face value of $\$ 100$, a current price of $\$ 100$, an annual coupon of $\$ 4$, and remaining life of 2 years. Therefore, from the above working process, we can conclude that the student should allocate $50.94 \%$ of his fund to invest zero-coupon bond and $49.06 \%$ of his fund to invest corporate coupon bond to make the one-off payment three years later.

Although this paper has a sufficient theoretical structure and derivation process, it still has some defects in the actual process of data collection and innovative modeling. In addition, according to the actual policy and the current situation of the world economic environment, this paper should also make some corresponding mention and adjustment. Future research should pay more attention to the macro direction of the world economy to provide the detailed allocation of bond portfolio and data simulation results for subsequent researchers to study

\section{REFERENCES}

[1]. Zvi Bodie, \& Alex Kane. (2011). Investments (9th edition)

[2]. Ivanova, Y. P. (2004). Developing domestic bond markets: Importance, alternatives, prerequisites and sequence (Order No. 1463331).

[3]. Teixeira, J. C. A. (2007). An empirical analysis of structural models of corporate debt pricing. Applied Financial Economics, 17(14), 1141.

[4]. Longstaff, F. A., \& Schwartz, E. S. (1993). Implementation of the longstaff-schwartz interest rate model. The Journal of Fixed Income, 3(2), 7. 
[5]. F.M. Redington. (1952). Review of the Principles of Life-Office Valuations, Journal of the Institute of Actuaries 78, no. 3:286-315

[6]. Lawrence Fisher and Roman L.Weil. (1971). Coping with the Risk of Interest Rate Fluctuations: Returns to bondholders from Naive and Optimal Strategies. Journal of Business 44, no.4

[7]. Lano, K., \& Haughton, H. (2019). Financial Software Engineering (1st ed. 2019.). Springer International Publishing. https://doi.org/10.1007/978-3-03014050-2

[8]. Macaulay, F. R. (1938). Some theoretical problems suggested by the movements of interest rates, bond yields and stock prices in the United States since 1856. New York, America: National Bureau of Economic Research.

[9]. La Grandville, O. (2001). Bond pricing and portfolio analysis protecting investors in the long run. MIT Press.

[10]. Lano, K., \& Haughton, H. (2019). Financial Software Engineering (1st ed. 2019.). Springer International https://doi.org/10.1007/978-3-030-14050-2

[11]. Murphy, C. (2021, March 04). How floating rate funds can offer yields in a rising rate market. Retrieved April 16, 2021, from https://www.investopedia.com/terms/f/floatingrate-fund.asp

[12]. Cohen, H. (1993). Beyond duration: Measuring interest rate exposure. Economic Review - Federal Reserve Bank of Atlanta, 78(2), 23.

[13]. TARK, C. S. (1987). Duration And An Alternative Bond Portfolio Immunization Strategy (Order No. 8802144). Available from ABI/INFORM Collection. (303660134).]

[14]. Fisher, L., \& Weil, R. L. (1971). COPING WITH THE RISK OF INTEREST-RATE FLUCTUATIONS: RETURNS TO BONDHOLDERS FROM NAIVE AND OPTIMAL STRATEGIES. The Journal of Business (Pre-1986), 44(3), 408.

[15]. Bodie, Z. (1988). Pension fund investment policy. Cambridge: National Bureau of Economic Research, Inc.

[16]. TARK, C. S. (1987). Duration And An Alternative Bond Portfolio Immunization Strategy (Order No. 8802144). Available from ABI/INFORM Collection. (303660134) 